\title{
FMR Study of Temperature Dependence of Magnetic Properties of Nanocrystalline $0.90\left(\mathrm{Fe}_{2} \mathrm{O}_{3}\right) / 0.10 \mathrm{ZnO}$
}

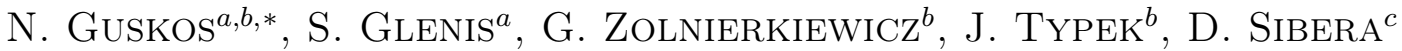 \\ AND U. NARKIEWICZ ${ }^{c}$ \\ ${ }^{a}$ Solid State Section, Department of Physics, University of Athens, Panepistimiopolis, 15 784, Greece \\ ${ }^{b}$ Institute of Physics, West Pomeranian University of Technology, Al. Piastów 17, 70-310 Szczecin, Poland \\ ${ }^{c}$ Institute of Chemical and Environmental Engineering, West Pomeranian University of Technology \\ al. Piastów 17, 70-310 Szczecin, Poland
}

(Received April 13, 2011)

\begin{abstract}
The nanocrystalline mixed system $0.90\left(\mathrm{Fe}_{2} \mathrm{O}_{3}\right) / 0.10 \mathrm{ZnO}$ has been prepared by coprecipitation and calcination processes. The phase composition of samples was determined by X-ray diffraction. The studied nanocrystalline sample is dominated by phase $\mathrm{Fe}_{2} \mathrm{O}_{3}$ but very small amounts of $\mathrm{ZnO}$ and $\mathrm{ZnFe}_{2} \mathrm{O}_{4}$ phases were also identified. The ferromagnetic resonance investigations of the obtained sample have been carried out in the temperature range from liquid helium to room temperature. The asymmetrical and very intense magnetic resonance line was recorded at all temperatures. A significant shift of spectra towards lower magnetic fields with decreasing temperature was observed. A very good fitting by two Lorentzian functions has been obtained which suggested the existence of a strong anisotropic magnetic interaction. Some similarities in behaviour of ferromagnetic resonance parameters of the present sample and the $0.95 \mathrm{Fe}_{2} \mathrm{O}_{3} \mathrm{Fe} 2 \mathrm{O} 3 / 0.05 \mathrm{ZnO}$ sample were noticed but the parameters values were essentially different. The gradients $\Delta H_{\mathrm{r}} / \Delta T$ (where $H_{\mathrm{r}}$ is the resonance field), the broadening processes of the resonance lines as well as the line amplitudes were changing more intensely changing with temperature in comparison to sample $0.95 \mathrm{Fe}_{2} \mathrm{O}_{3} \mathrm{Fe} 2 \mathrm{O} 3 / 0.05 \mathrm{ZnO}$. The following values $\Delta H_{\mathrm{r}} / \Delta T$ are obtained: $16.7(1) \mathrm{Gs} / \mathrm{K}$ and 20.7(1) Gs/K over the $60 \mathrm{~K}$ temperatures where below $40 \mathrm{~K}$ is $41.5(1) \mathrm{Gs} / \mathrm{K}$ and $56.0(1) \mathrm{Gs} / \mathrm{K}$. The reorientation processes were more active at low temperatures for smaller concentrations of magnetic nanoparticles.
\end{abstract}

PACS: 75.50.Tt, 76.30.Fc, 76.50.+g

\section{Introduction}

Low and high concentration in nanoscale level of magnetic particles has attracted great interest for investigation of magnetic interactions which could transform essential physical properties different materials e.g. [1-13]. The mixed $n\left(\mathrm{Fe}_{2} \mathrm{O}_{3}\right) /(1-n) \mathrm{ZnO}$ nanocomposites could form two coexisting important magnetic phases $\left(\gamma-\mathrm{Fe}_{2} \mathrm{O}_{3}\right.$ and $\mathrm{ZnFe}_{2} \mathrm{O}_{4}$ ) and for higher value of $n$ they are dominated by iron oxide [14-17]. Study of such systems can provide important information on the reorientation processes of highly correlated spin systems and the role of intermolecular dipole-dipole interactions.

The aim of this report is the investigation of dynamical magnetic properties of nanostructural $0.90\left(\mathrm{Fe}_{2} \mathrm{O}_{3}\right)$ / $0.10 \mathrm{ZnO}$ composite prepared by wet chemical method by using ferromagnetic resonance (FMR) spectroscopy at different temperatures. The characterization of the composite has been done by scanning electron microscopy (SEM) and X-ray diffraction (XRD).

* corresponding author; e-mail: ngouskos@phys.uoa.gr

\section{Experimental}

The samples were synthesized using wet chemistry method. The mixture of zinc and iron hydroxides was obtained by an addition of $26 \%$ ammonia solution to the $20 \%$ solution of zinc nitrate (V) hexahydrate and iron (III) nitrate $(\mathrm{V})$ tetrahydrate. The obtained residue was filtered, dried and calcined at $573 \mathrm{~K}$ for $1 \mathrm{~h}$. A detailed method of preparation is described elsewhere [14, 15]. The samples were characterized by a number of methods listed below. XRD measurements were conducted using X'Pert X-ray powder diffractometer with $\mathrm{Cu} K_{\alpha}$ radiation $(1.54056 \AA)$. The mean crystallite size (MCS) was calculated on the basis of Scherrer's formula. The raw data was processed using X'Pert Highscore software. The morphology of the obtained samples was investigated by using scanning electron microscopy (SEM-LEO 1530). The real chemical composition of samples was determined using inductively coupled plasma atomic emission spectroscopy (Yvon-Jobin, France). The specific surface area of the nanopowders was determined by the BrunauerEmmett-Teller (BET) method (nitrogen adsorption) using Gemini 2360 of Micromeritics. The helium pycnometer AccuPyc 1330 of Micromeritics was applied to deter- 
mine the density of powders.

The FMR spectra were recorded on conventional X-band $(\nu=9.4 \mathrm{GHz})$ Bruker E500 EPR spectrometer with $100 \mathrm{kHz}$ magnetic field modulation. Samples containing around $20 \mathrm{mg}$ of nanopowder were placed in $4 \mathrm{~mm}$ diameter quartz tubes. The measurements were carried out in the temperature range of 4-300 K using an Oxford helium-flow cryostat.

\section{Experimental results and discussion}

The application of high temperatures in the co-precipitation/calcination synthesis of oxides is the main reason for grain agglomeration. To avoid this process allow calcinations temperature of $300.1^{\circ} \mathrm{C}$ was used. Table summarizes the results of the density and specific surface area measurements to gather with sample chemical composition determined by ICP-AES measurements, in perfect agreement with the nominal one calculated from the initial concentration of the precursor salts. The compared with nanostructural composition $0.95\left(\mathrm{Fe}_{2} \mathrm{O}_{3}\right) /$ $0.05 \mathrm{ZnO}$ is lowered specific surface area and increases concentration of magnetic nanoparticles oxide irons [13]. $\mathrm{XRD}$ analysis has shown that the main phase is the cubic spinel $\gamma-\mathrm{Fe}_{2} \mathrm{O}_{3}$ (Fig. 1). However, low intensity diffraction peaks corresponding to hexagonal $\mathrm{ZnO}$ (blue vertical line) and $\mathrm{ZnFe}_{2} \mathrm{O}_{4}$ (red vertical line) are also traced (inset of Fig. 1). Peaks corresponding to $\mathrm{ZnFe}_{2} \mathrm{O}_{4}$ are not clearly visible because of a very low content of this phase. The mean crystallite size of the $\mathrm{Fe}_{2} \mathrm{O}_{3}$ phase, calculated by the Scherrer formula, was found to be $24 \mathrm{~nm}$. SEM images reveal the agglomerated structure of the synthesized material, as shown in Fig. 2. The agglomerates have a mean size of about $60 \mathrm{~nm}$ and are bound to each other creating large structures. The powder exhibits homogeneous structure, with a distribution of the agglomerates' sizes in a narrow range. Most likely the observed structures originate from the $\mathrm{Fe}_{2} \mathrm{O}_{3}$ phase.

TABLE

Characteristic parameters of $0.90\left(\mathrm{Fe}_{2} \mathrm{O}_{3}\right) / 0.10 \mathrm{ZnO}$ and $0.95\left(\mathrm{Fe}_{2} \mathrm{O}_{3}\right) / 0.05 \mathrm{ZnO}$ [13] samples.

\begin{tabular}{c|c|c|c|c|c}
\hline \hline $\begin{array}{c}\text { Nominal } \\
\text { concentration } \\
\mathrm{Fe}_{2} \mathrm{O}_{3}[\mathrm{wt} \%]\end{array}$ & $\begin{array}{c}\text { Nominal } \\
\text { concentration } \\
\mathrm{ZnO}[\mathrm{wt} \%]\end{array}$ & $\begin{array}{c}\text { Density } \\
{\left[\mathrm{g} / \mathrm{cm}^{3}\right]}\end{array}$ & $\begin{array}{c}\text { Surface } \\
\text { area } \\
{\left[\mathrm{m}^{2} / \mathrm{g}\right]}\end{array}$ & $\begin{array}{c}\text { Measured } \\
\text { concentration } \\
\mathrm{Fe}_{2} \mathrm{O}_{3}[\mathrm{wt} \%]\end{array}$ & $\begin{array}{c}\text { Measured } \\
\text { concentration } \\
\mathrm{ZnO}[\mathrm{wt} \%]\end{array}$ \\
\hline 90 & 10 & 4.8 & 103 & 89.8 & 8.6 \\
$95^{*}$ & 5 & 4.8 & 83 & 95.4 & 4.6
\end{tabular}

In Fig. 1 the FMR spectra of nanostructural $0.90\left(\mathrm{Fe}_{2} \mathrm{O}_{3}\right) / 0.10 \mathrm{ZnO}$ composite at different temperatures are given. The very intense and asymmetric resonance line is shown displaying a strong temperature dependence. The resonance line is centered at $g_{\text {eff }}=$ 2.061(1) $\left(H_{\mathrm{r}}=3260(1) \mathrm{Gs}\right)$ with linewidth $\Delta H_{\mathrm{pp}}=$ 690(1) Gs while for nanostructural $0.95\left(\mathrm{Fe}_{2} \mathrm{O}_{3}\right) / 0.05 \mathrm{ZnO}$ composite the following values were obtained: $g_{\text {eff }}=$ 2.104(1) $\left(H_{\mathrm{r}}=3194(1) \mathrm{Gs}\right)$ with linewidth $\Delta H_{\mathrm{pp}}=$ 820(1) Gs [13]. Essential differences are registered for the values of the resonance field and linewidth in both nanocomposites differing in concentration of iron oxide. The FMR line asymmetry suggests that the observed signal could be composed of two resonance lines. The experimental FMR resonance line could be fitted by two Lorentzian functions with different amplitudes and linewidths. The linewidth $\left(\Delta H_{\mathrm{pp}}\right)$ of the FMR signal is comparable to the value of the resonance field. The fitting function $f(H)$ has to include Lorentzian absorption derivatives corresponding to the both, right and left, circularly polarized components $A\left(H_{+}\right)$and $A\left(H_{-}\right)$of the linearly polarized microwave field $f(H)=A\left(\overline{H_{+}}\right)+$ $A\left(H_{-}\right)$.

In Fig. 3b an example of fitting the experimental magnetic resonance spectrum with two component lines at
$T=90 \mathrm{~K}$ is given. The decompositions of the spectra registered at different temperatures on two lines (line 1 and 2) allowed calculation of the spectral parameters (signal amplitude, resonance field, and linewidth).

Figure 4 presents the temperature dependence of the FMR parameters for both resonance lines. The nanoparticles for which the applied magnetic field is parallel to the easy axis of magnetization produce a high-field line (line 1) while the nanoparticles with an easy axis perpendicular to the applied field generate a resonance field at a low-field (line 2). After decomposition, at room temperature the resonance lines are given the following values of $g$ and $\Delta H_{\mathrm{pp}}: g_{1}=2.041(1)\left(H_{\mathrm{r}}=3311(1) \mathrm{Gs}\right)$ with linewidth $\Delta H_{\mathrm{pp}}=541(3)$ Gs and $g_{2}=2.206(1)\left(H_{\mathrm{r}}=\right.$ $3036(1)$ Gs) with linewidth $\Delta H_{\mathrm{pp}}=342(5)$ Gs for lines 1 and 2 , respectively (for $0.95\left(\mathrm{Fe}_{2} \mathrm{O}_{3}\right) / 0.05 \mathrm{ZnO}$ composite $g_{1}=2.026(2) \quad\left(H_{\mathrm{r}}=3340(1) \mathrm{Gs}\right)$ with linewidth $\Delta H_{\mathrm{pp}}=294(5)$ Gs and $g_{2}=2.174(2)\left(H_{\mathrm{r}}=3118(1) \mathrm{Gs}\right)$ with linewidth $\Delta H_{\mathrm{pp}}=675(5)$ Gs [13]). A significant difference in the magnetic response is observed between lines 1 and 2 . For both lines the resonance field $\left(H_{\mathrm{r}}\right)$ shifts towards low magnetic fields with temperature decrease and this shift is more intense in the low temperature range. The resonance condition is the following: 


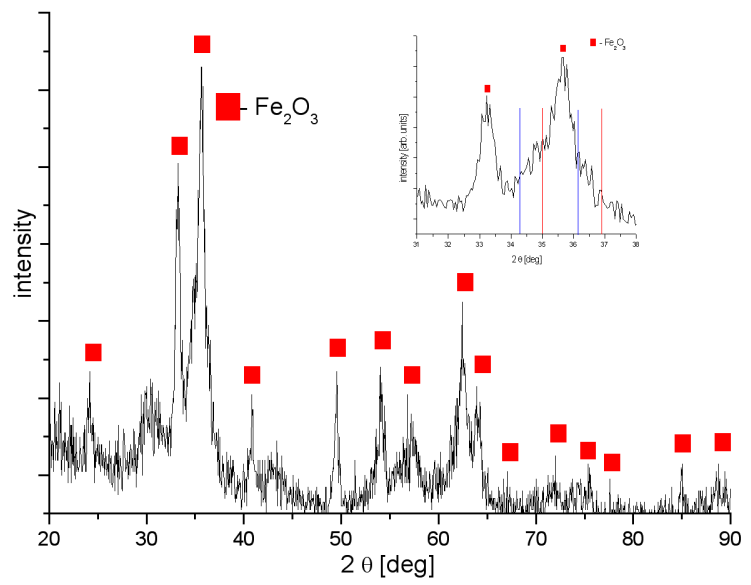

Fig. 1. XRD pattern showing the most intense peaks positions of $\mathrm{ZnO}$ (blue line) and $\mathrm{ZnFe}_{2} \mathrm{O}_{4}$ (red line). Red squares mark $\mathrm{Fe}_{2} \mathrm{O}_{3}$ peaks. The inset shows the most intense line in an expanded scale.

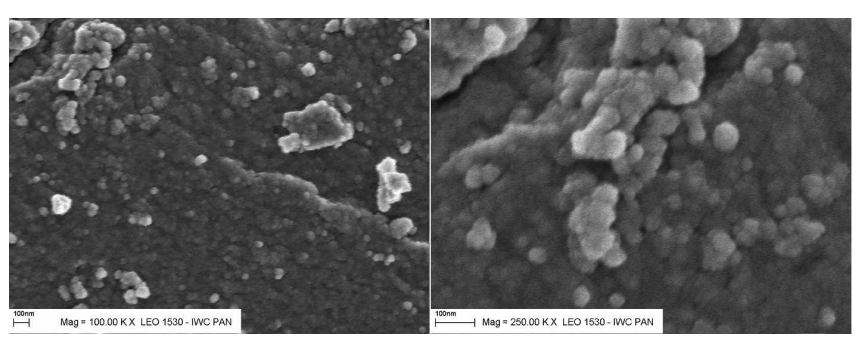

Fig. 2. SEM images of the $0.95\left(\mathrm{Fe}_{2} \mathrm{O}_{3}\right) / 0.05 \mathrm{ZnO}$ nanopowder.

$$
\begin{aligned}
& h \nu=g \mu_{\mathrm{B}}\left(H_{0}-H_{\mathrm{int}}\right), \\
& H_{\mathrm{int}}=H_{\mathrm{dip}}+H_{\mathrm{dem}}+H_{\mathrm{dip}^{\prime}},
\end{aligned}
$$

where $h$ - the Planck constant, $\nu$ - microwave frequency, $\mu_{\mathrm{B}}$ - the Bohr magneton, $H_{0}$ - external applied magnetic field and $H_{\text {int }}$ - internal magnetic field induced by reorientation processes by spin system, $H_{\text {dip }}$ - magnetic dipole interaction inside nanoparticle, $H_{\mathrm{dem}}-$ demagnetization field and $H_{\mathrm{dip}^{\prime}}$ - magnetic dipole interaction between agglomerates. $H_{\text {int }}$ is anisotropic where strong temperature dependence is observed. The introduced temperature gradient $\Delta H_{\mathrm{r}} / \Delta T$ (ratio of resonance field change vs. temperature) gives important information about reorientation processes of correlated spin system. Four temperature ranges with large differences are observed for the $\Delta H_{\mathrm{r}} / \Delta T$ gradient: $290 \mathrm{~K}$ to $60 \mathrm{~K}$, $\Delta H_{\mathrm{r}} / \Delta T=3.6(2) \mathrm{Gs} / \mathrm{K}$ and $\Delta H_{\mathrm{r}} / \Delta T=7.4(2) \mathrm{Gs} / \mathrm{K}$, from 60 to $49 \mathrm{~K}$ plateau is observed, $\Delta H_{\mathrm{r}} / \Delta T=0$ for both resonance lines, and below $40 \mathrm{~K} \Delta H_{\mathrm{r}} / \Delta T=$ $75.4(2) \mathrm{Gs} / \mathrm{K}$ and $\Delta H_{\mathrm{r}} / \Delta T=41.9(2) \mathrm{Gs} / \mathrm{K}$ for line 1 and 2 , respectively (for $0.95\left(\mathrm{Fe}_{2} \mathrm{O}_{3}\right) / 0.05 \mathrm{ZnO}$ composite $\Delta H_{\mathrm{r}} / \Delta T=3.7(1) \mathrm{Gs} / \mathrm{K}$ and $\Delta H_{\mathrm{r}} / \Delta T=8.3(1) \mathrm{Gs} / \mathrm{K}$, from 60 to $40 \mathrm{~K}$ plateau is observed, $\Delta H_{\mathrm{r}} / \Delta T=0$ for both resonance lines, and below $40 \mathrm{~K} \Delta H_{\mathrm{r}} / \Delta T=$ 40.5(1) Gs/K and $\left.\Delta H_{\mathrm{r}} / \Delta T=49.6(1) \mathrm{Gs} / \mathrm{K}[13]\right)$. The

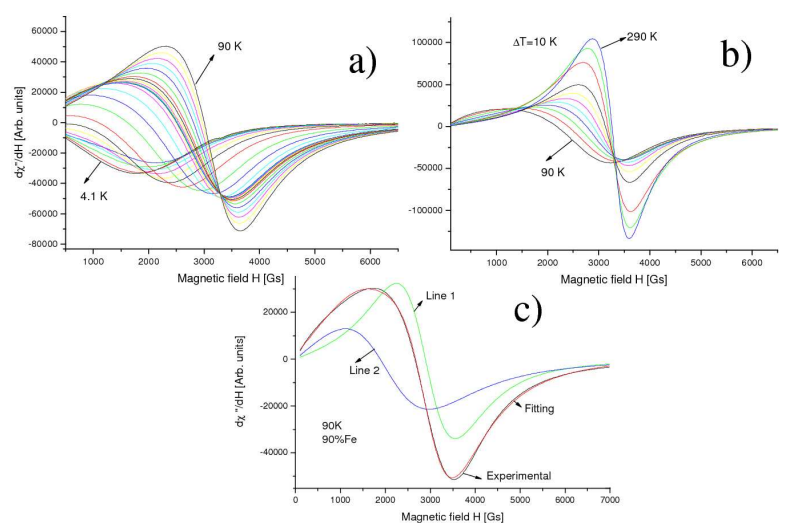

Fig. 3. FMR spectra of $0.90\left(\mathrm{Fe}_{2} \mathrm{O}_{3}\right) / 0.10 \mathrm{ZnO}$ in the low temperature range (a), in the high temperature range (b) and decomposition of observed spectrum on two components (c).
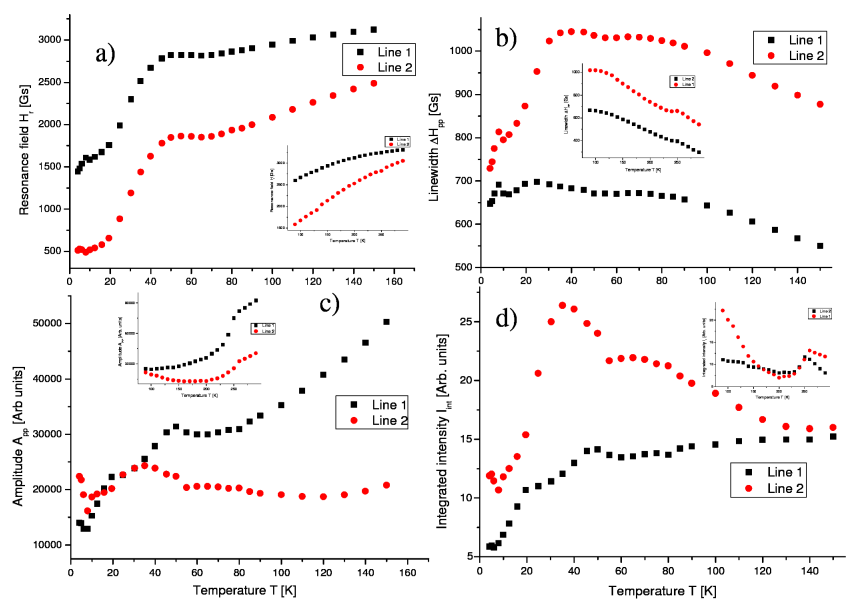

Fig. 4. The temperature dependence of the FMR parameters in low temperature range: resonance field $H_{\mathrm{r}}(\mathrm{a})$, linewidth $-\Delta H_{\mathrm{pp}}(\mathrm{b})$, amplitude $-A_{\mathrm{pp}}(\mathrm{c})$, and integrated intensity $-I_{\text {int }}(\mathrm{d})$. The insets show the same dependence in high temperature range.

reorientation processes of magnetic moments for the resonance line 2 are more intense, especially at high temperatures $\left(\Delta H_{\mathrm{r}} / \Delta T(\right.$ line 2$) / \Delta H_{\mathrm{r}} / \Delta T($ line 1$)=2.1$ above $60 \mathrm{~K})$, while at low temperatures $\left(\Delta H_{\mathrm{r}} / \Delta T\right.$ (line 2$) /$ $\Delta H_{\mathrm{r}} / \Delta T($ line 1$)=0.6$ below $\left.40 \mathrm{~K}\right)\left(\right.$ for $0.95\left(\mathrm{Fe}_{2} \mathrm{O}_{3}\right) /$ $0.05 \mathrm{ZnO}$ composite this ratio is the following: 2.3 and 1.2 [13]). Additionally, it increases drastically below $48 \mathrm{~K}$, while for $0.95\left(\mathrm{Fe}_{2} \mathrm{O}_{3}\right) / 0.05 \mathrm{ZnO}$ composite it is shifted to $41 \mathrm{~K}$ [13]. Even small concentration of magnetic nanoparticles influences significantly the reorientation of the correlated spin system at low temperatures.

The linewidth increases with decreasing temperature and below $35 \mathrm{~K}$ drops for resonance line 2 while such intense process for line 1 is not observed (Fig. 4b). The amplitude and integrated intensity of both resonance lines have increased with an increase in temperature for both lines, where for line 1 it is more intense than for line 2 , 
while it is drastically changed below $35 \mathrm{~K}$ (Fig. 4c and d). Some anomaly is observed at $260 \mathrm{~K}$ which is shifted by $20 \mathrm{~K}$ for a composite with higher concentration of the magnetic nanoparticles [13]. The freezing state influence significantly reorientation processes of correlated spin systems. The higher concentration of the magnetic centers is connected with resonance line 1 but the broadening processes is higher for the resonance line 2 . The relaxation processes transfer excited energy between correlated spin systems could influence the broadening processes. The decrease of the integrated intensity with temperature decrease in high temperature range is a characteristic behaviour of magnetic nanoparticles (or clusters) in the form of agglomerates embedded in a nonmagnetic matrix $[9,10,12]$. The resonance line 1 exhibits a smoother variation of integrated intensity with temperature because the correlated spin system connected with line 1 consist in higher concentration and it allows for the possibility of different reorientation processes of the magnetic moments that could be responsible for the strong anisotropic magnetic interactions. Additionally, the "viscosity" of materials could influence the reorientation of spin correlated system [18].

\section{Conclusions}

The nanostructural $0.90\left(\mathrm{Fe}_{2} \mathrm{O}_{3}\right) / 0.10 \mathrm{ZnO}$ composite was prepared by a wet chemical method and characterized by SEM and XRD. The spectra were investigated by FMR over a wide temperature range. The obtained FMR spectra were analysed in terms of two separate resonance lines which reveals a strong anisotropic temperature dependence of the FMR parameters. The slowly decreasing concentration of magnetic nanoparticles in strongly correlated spin system significant influence the reorientation processes.

\section{References}

[1] D.L. Leslie-Pelecky, R.D. Rieke, Chem. Mater. 8, 1770 (1996).

[2] R.H. Kodama, A.E. Berkowitz, Phys. Rev. B 59, 6321 (1999).
[3] J.L. Dormann, D. Fiorani, E. Tronc, Adv. Chem. Phys. 98, 283 (1997).

[4] B. Martínez, X. Obradors, Ll. Balcells, A. Rouanet, C. Monty, Phys. Rev. Lett. 80, 181 (1998).

[5] R. Berger, J. Kliava, J. Magn. Magn. Mater. 205, 328 (1999).

[6] Y.A. Koksharov, S.P. Gubin, I.D. Kosobudsky, G.Y. Yurkov, D.A. Pankratov, L.A. Ponomarenko, M.G. Mikheev, M. Beltran, Y. Khodorkovsky, A.M. Tishin, Phys. Rev. B 63, 012407 (2000).

[7] X. Batlle, A. Labarta, J. Phys. D 35, R15 (2002).

[8] J. Majszczyk, N. Guskos, J. Typek, M. Maryniak, Z. Roslaniec, M. Kwiatkowska, D. Petridis, J. Non-Cryst. Solids 352, 4279 (2006).

[9] N. Guskos, V. Likodimos, S. Glenis, M. Maryniak, M. Baran, R. Szymczak, Z. Roslaniec, M. Kwiatkowska, D. Petridis, J. Nanosci. Nanotechnol. 8, 2127 (2008).

[10] J. Typek, N. Guskos, A. Szymczyk, D. Petridis, J. Non-Cryst. Solids 354, 4256 (2008).

[11] N. Guskos, G. Zolnierkiewicz, J. Typek, J. Blyszko, W. Kiernozycki, U. Narkiewicz, Rev. Adv. Mat. Sci. 23, 113 (2010).

[12] N. Guskos, J. Typek, B.V. Padlyak, Yu.K. Gorelenko, I. Pelech, U. Narkiewicz, E. Piesowicz, E. Senderek, A. Guskos, Z. Roslaniec, J. Non-Cryst. Solids 356, 1893 (2010).

[13] N. Guskos, S. Glenis, G. Zolnierkiewicz, J. Typek, D. Sibera, J. Kaszewski, D. Moszyński, W. Łojkowski, U. Narkiewicz, submitted for publication in Cent. Eur. J. Phys.

[14] U. Narkiewicz, D. Sibera, I. Kuryliszyn-Kudelska, L. Kilanski, W. Dobrowolski, M. Romcevic, Acta Phys. Pol. A 113, 1695 (2008).

[15] D. Sibera, U. Narkiewicz, N. Guskos, G. Zołnierkiewicz, J. Phys., Conf. Series 146, 012014 (2009).

[16] N. Guskos, G. Zolnierkiewicz, J. Typek, D. Sibera, U. Narkiewicz, Rev. Adv. Mater. Sci. 23, 224 (2010).

[17] N. Guskos, G. Zolnierkiewicz, J. Typek, D. Sibera, U. Narkiewicz, , W. Łojkowski, Acta Phys. Pol. A 120, 1074 (2011).

[18] M.R. Dudek, N. Guskos, E. Senderek, Z. Roslaniec, J. Alloys Comp. 504, 289 (2010). 